\title{
The potential role of some amino acids with different concentrations, application types and times to manage Meloidogyne javanica on tomato plants
}

\author{
Selim, M. E. 1; Galal, Neveen, M. ${ }^{2}$ and Mahdy, M. E. ${ }^{1}$
}

1- Dept. of Agric. Botany, Fac. of Agric., Menofia Univ., Shebin El Kom, Egypt.

2- Nematode Research Dept., Plant Pathology Research Institute, Agric. Res. Centre, Giza, Egypt.

\begin{abstract}
In present study four different amino acids i.e. DL-Valine, DL-Methonine, DLAsparagine and DL-Arginine with five different concentrations (50, 100, 150, 200 and $400 \mathrm{mg} / \mathrm{ml}$ ) and two different application methods (soil drench and foliar spray) at two different application times (three days before and three days after nematode inoculation) were tested under both laboratory and greenhouse conditions to evaluate their influences on root-knot nematode Meloidogyne javanica and growth criteria of treated tomato plants. The results revealed that all tested amino acids at concentration of $400 \mathrm{mg} / \mathrm{ml}$ reduced significantly both eggs hatching and juveniles' viability compared to control (nematode treated with tap water) under in vitro conditions. The highest percentage of non-hatched eggs (68\%) and dead juveniles (81\%) was recorded by DL-Methonine amino acid followed by DL-Asparagine which percentage of non-hatched eggs and dead juveniles recorded $60 \%$ and $80 \%$, respectively.
\end{abstract}

Key words: Meloidogyne, root knot nematode control, green chemistry, natural control

\section{INTRODUCTION}

Tomato (Lycopersicum esculentum L.) is considered one of the most popular and nutritious vegetable crop in Egypt. According to FAO stat (Food and Agriculture Organization on United Nations) in 2020 the total planted area with tomato was 428182 faddens which producing about 6751856 tons/Fadden a year of production. This crop is attacking by several serious plant pathogens such as fungi, bacteria, virus and plant parasitic nematodes causing several harmful effects and diseases consequently severe losses in yield and economic income. Root-knot nematodes Meloidogyne species are one of the highly important soil-borne pathogens that cause great economic damages to horticultural and field crops and considered one of the most dangerous plant parasitic nematodes which can infect approximately all the world main crop plants (Oka et. al., 2000). They have the potential to cause up to $80 \%$ losses in vegetables in tropical and subtropical counties (Hussain et.al., 2011). Different methods can be utilized for controlling Meloidogyne 
species such as cultural practices, resistant cultivars, and chemical nematicides which are easy for application and more effective. Chemical nematicides have harmful effects for air, soil and water (Alam, 1987) and very expensive particularly for poor farmers in Egypt. Thus for these reasons, the safety alternative strategy methods are highly needed to manage root-knot infections. From the alternative methods to manage rootknot nematodes Meloidogyne spp. are amino acids. One of their advantages, they are used with very relative doses which allow to use small particular amount for large infestation control. So, our search aimed to use the safety and cheap alternative compounds at different concentrations, application types and times to manage root-knot nematode (Meloidogyne javanica) on tomato plants.

\section{MATERIALS AND METHODS}

The in vitro and in vivo assays were conducted at Agric. Botany Dept., Fac. of Agric., Menofia Univ., Egypt, to evaluate the efficacy of four different amino acids i.e. DL-valine, DLmethonine, DL-asparagine and DLarginine at different concentrations $(50,100,150,200$ and $400 \mathrm{mg} / \mathrm{ml})$ using two different application types i.e. soil drench and foliar spray and two different applications times (three days before and after, nematodes inoculation) to manage root- knot nematode ( $M$. javanica) on tomato plants (Lycopersicum esculentum cv. Super strain B).

Pure culture of $M$. javanica was established from single egg mass on tomato plants under greenhouse conditions at $25^{\circ} \mathrm{C} \pm 2$. Nematode species identification was carried out according to the perennial patterns technique (Taylor and Sasser, 1978). Root-knot nematode eggs were extracted from heavily galled roots by using $1.5 \%$ sodium hypochlorite solution $(\mathrm{NaOCl})$ technique as described by (Hussey and Barker, 1973).

\section{In vitro experiment}

The amino acids were tested for their effectiveness at different concentrations as mentioned before against egg hatching and larvae mortality of $M$. javanica under laboratory conditions.

\section{A. Egg hatching:}

Three hundred eggs in $0.1 \mathrm{ml}$ of distilled water placed in $0.9 \mathrm{ml}$ of different concentrations of the different amino acids in a 72-well micro-titre plate to evaluate the effectiveness of the different concentrations of amino acids on egg hatching. Each individual treatment replicated 6 times. Eggs placed in distilled water served as a control. The well micro-titre plate was incubated at $25^{\circ} \mathrm{C} \pm 2$ under lab. conditions. The percentage of hatched eggs was calculated in 100 eggs after 6 days of incubation under stereomicroscope using counting dish.

\section{B. Larvae mortality:}

Three hundred freshly hatched larvae in $0.1 \mathrm{ml}$ distilled water were placed in $0.9 \mathrm{ml}$ of the different amino acids concentrations in a 72 well micro-titre plate to evaluate its effectiveness on percentage of larvae mortality. Each 
treatment replicated 6 times. Larvae in distilled water only served as a control. The well micro-titer plate was incubated under lab. conditions at $25^{\circ} \mathrm{C} \pm 2$ and the percentage of the dead larvae were recorded in 100 larvae after 6 days using counting dish under stereomicroscope. To confirm that the larvae are dead after the incubation periods (6 days), all treated larvae with the different concentrations of the tested amino acids were washed with distilled water and incubated for 24 hours to confirm if they were dead or anesthetic.

\section{In vivo experiment:}

Tomato cultivar Super strain B which is susceptible to the root-knot nematode was used in greenhouse experiment. Three weeks old tomato seedlings were grown in plastic pots $(15 \mathrm{~cm}$ in diameter) filled with $2 \mathrm{~kg}$ unsterilized mixture of sandy-clay soil $(2: 1, v / v)$. Each pot contained one seedling. All four different amino acids were applied at a one single dose (400 $\mathrm{mg} / \mathrm{ml}$ ) as it was the effective dose according to in vitro test. Amino acids were applied at two different application types separately, (a) soil drench by receiving each plant $10 \mathrm{ml}$ around root zone, (b) foliar spraying where each plant was sprayed with 10 $\mathrm{ml}$ of each individual amino acid on a whole foliar system of plant. Amino acids were applied in two different application times, (a) three days before nematode inoculation, (b) three days after nematode inoculation. $M$. javanica eggs were extracted as mentioned before by the technique of (Hussey and Barker, 1973). Three thousands nematodes eggs were pipetting into 4 holes made around tomato roots. Un-treated plants served as a control. Each treatment was replicated 3 times. Plants were arranged in a completely randomized block design under greenhouse conditions at $25^{\circ} \mathrm{C} \pm 2$. Plants were watered daily and fertilized weekly by receiving $5 \mathrm{ml}$ of $2 \mathrm{~g} / \mathrm{L}$ NPK (20:20:20). Two months after nematode inoculation, nematode parameters i.e. No. of galls, egg masses/root system, No. of larvae $/ 250 \mathrm{~g}$ soil (Goodey, 1957), nematode final population (Pf), reproduction factor (Rf) and root galling were determined. Rate of nematode reproduction factor was recorded according to the equation:

$\mathrm{Rf}=\mathrm{pf} / \mathrm{pi}$ where: $\mathrm{pi}=$ initial inoculation (Norton, 1978).

Root galling index was calculated according to (Taylor and Sasser, 1978) where:

$0=$ no galls or egg masses

$1=1$ to 2 galls or egg masses

$2=3-10$ galls or egg masses

$3=11-30$ galls or egg masees

$4=31-100$ galls or egg masses

$5=$ more than 100 galls or egg masses

Egg masses were stained prior to counting by dipping the infected roots in Phloxin-B solution $(0.015 \%)$ for 20 minutes as described by Daykin and Hussey (1985). Plant growth characters i.e. shoot and root fresh weights $(\mathrm{g})$ as well as plant height $(\mathrm{cm})$ were recorded. Chemical constitutions i.e. antioxidant enzyme activities of peroxidase (PO), polyphenol oxidase (PPO), catalase were also estimated in fresh leaves according to methods of 
Broesh (1954), Fehrman and Dimond (1967), Bach and Oparin (1968), respectively.

\section{Statistical analysis}

All obtained data were analyzed using analysis of variance (ANOVA) among treatments. Means were compared by least significant differences (LSD) at $p$ $\leq 0.05$ as described by Song and Keane (2006).

\section{RESULTS}

Effect of five different concentrations i.e. $50,100,150,200$ and $400 \mathrm{mg} / \mathrm{ml}$ from each individual tested amino acid (DL-Valine, DL-Methonine, DLAsparagine, DL-Arginine) on egg hatching of $M$. javanica nematode was evaluated under laboratory conditions. The obtained data illustrated in (Fig. 1) revealed that most of the tested amino acids significantly inhibited egg hatching compared to control (eggs treated with tap water). Moreover, results confirmed that increasing the concentration of tested amino acids resulted in increasing the inhibition of nematode eggs hatching. Thus the highest inhibition of eggs hatching was observed with concentration of 400 $\mathrm{mg} / \mathrm{ml}$ of tested amino acids. Indeed, the lowest percentage (32 and $40 \%$ ) of hatched eggs at concentration of $400 \mathrm{mg} / \mathrm{ml}$ was recorded with DLMethonine and DL-Asparagine, respectively (Fig. 1).

Similar results were recorded with aspect to influence of the tested amino acids at five different concentrations i.e. $50,100,150,200$ and $400 \mathrm{mg} / \mathrm{ml}$ on mortality of nematode juveniles (Fig. 2). The highest mortality percentage (81 and $80 \%)$ was detected at concentration of $400 \mathrm{mg} / \mathrm{ml}$ with DL-Methonine and DLAsparagine, respectively (Fig. 2). Contrary, the lowest percentage of dead juveniles $(51 \%)$ at same concentration $(400 \mathrm{mg} / \mathrm{ml})$ was detected with DL-Arginine, followed by DL-Valine (57\%).

The influence of four different amino acids applied with two different application methods (soil drench and foliar spray) at two different application times (three days before and three days after nematode inoculation) on physiological criteria i.e. plant height $(\mathrm{cm})$, shoot and root fresh weights $(\mathrm{g})$ were determined under greenhouse conditions. The obtained results showed that except of DL-Asparagine amino acid, the three other amino acids tested (DL-Valine, DL-Methonine and DL-Arginine) increased the plant height of treated plants compared to control (inoculated plants with nematode only) when amino acids were applied as soil drench 3 days before nematode inoculation (Fig.3). On the other hand, only significant deference in plant height was recorded with DL-Valine amino acid in aspect to influence on plant height parameter with soil drench application method when amino acids used 3 days after nematode inoculation (Fig.3). With foliar spray of amino acids 3 days before nematode inoculation, the results showed that only two amino acids (DL-Valine and DL-Methonine) increased plant height of treated tomato plants compared to control (inoculated with nematode only) (Fig.3). Contrary, no significant differences were recorded between tomato plants sprayed individually with the four tested amino acids 3 days after nematode inoculation and control plants (Fig.3). 


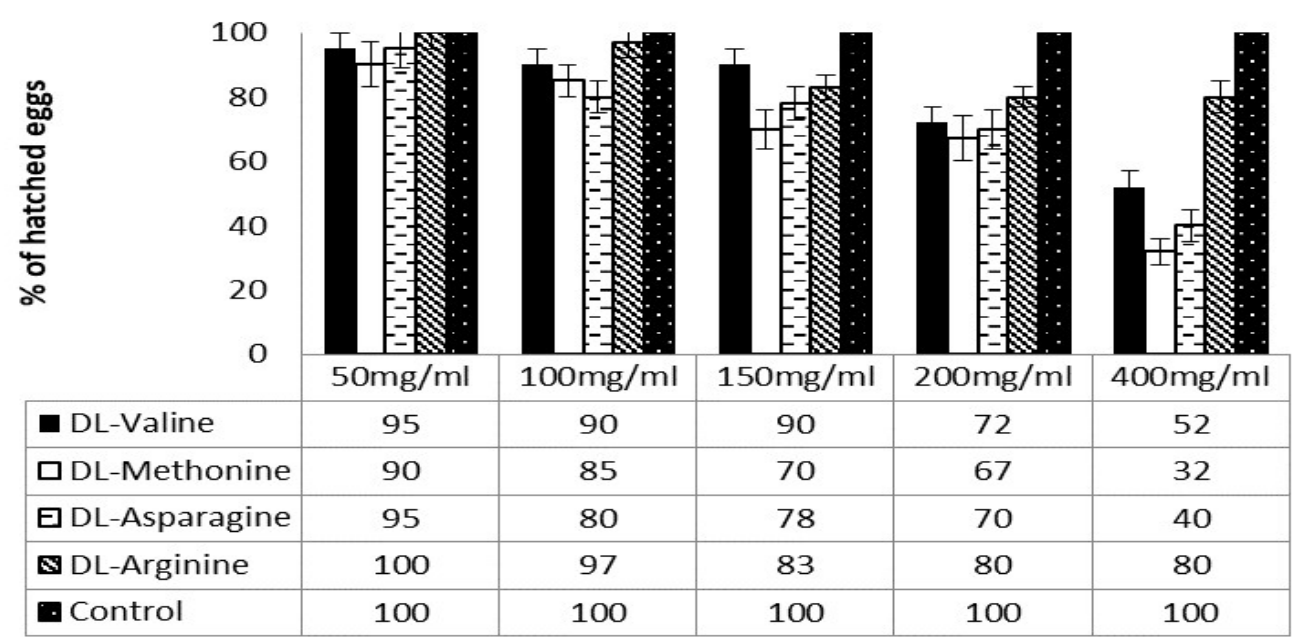

Fig. (1). Effect of different amino acids at different concentrations on percentage of eggs hatching of Meloidogyne javanica under in vitro conditions

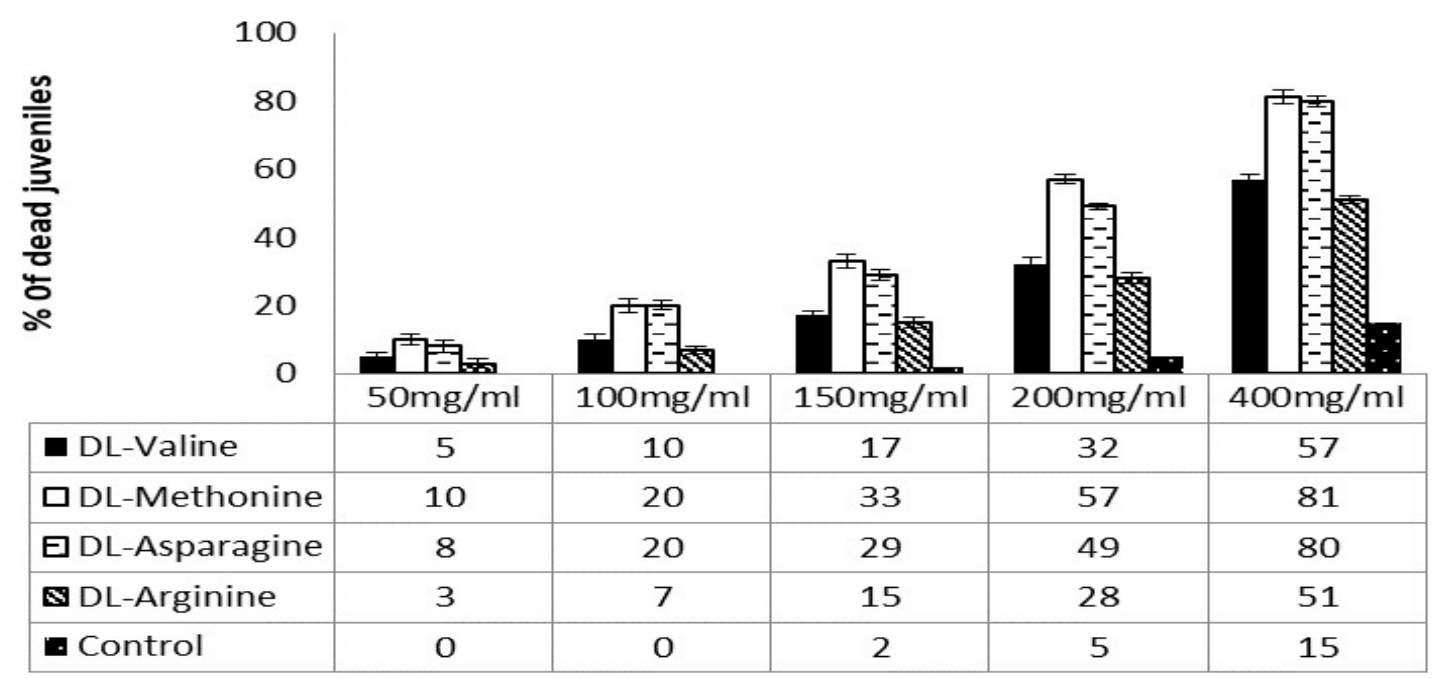

Fig. (2). Mortality percentage of Meloidogyne javanica juveniles treated with different concentrations of five different amino acids under in vitro conditions.

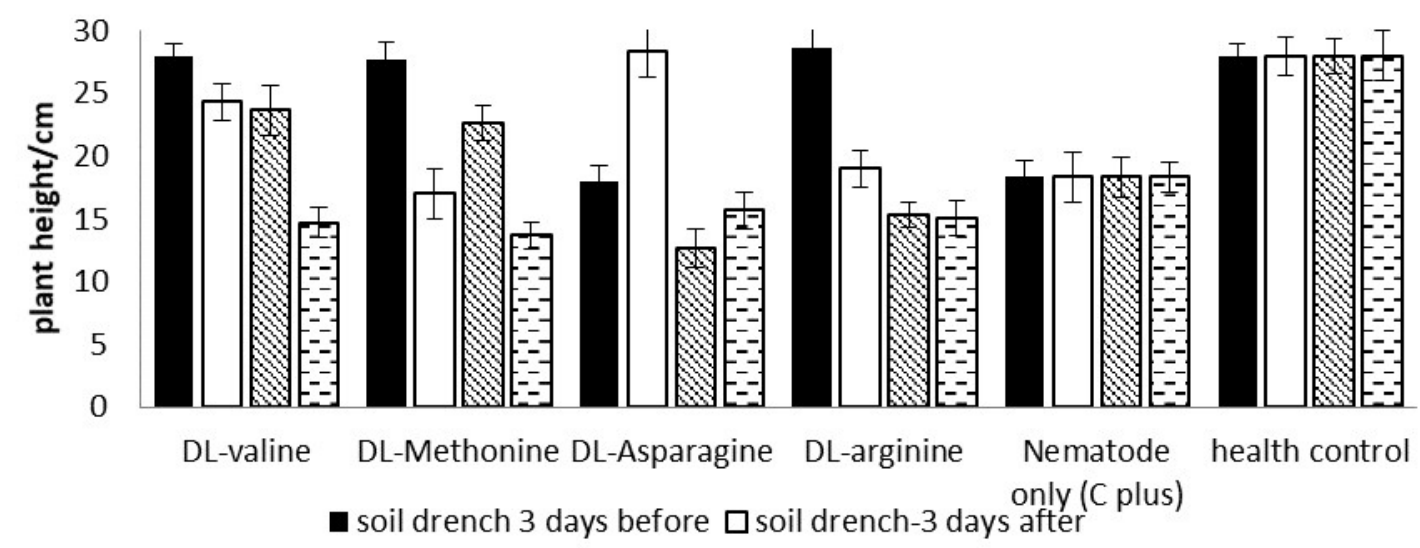

因 foliar spray-3 days before $\mathbf{0}$ foliar spray -3 days after

Fig. (3). Plant height recorded with treated and untreated tomato plants with valine, methonine, asparagine and arginine amino acids using soil drench and foliar spray application methods at 3 days before and after nematode inoculation times. 
The data recorded with shoot weight revealed that, the all tested amino acids except of methonine affected positively the shoot weight of treated plants either with soil drench or foliar application at 3 days before and 3 days after nematode inoculation compared to the control plants (Fig. 4).

The highest shoot weight (31.2 and $28.2 \mathrm{~g}$ ) was recorded with asparagine amino acid as soil drench 3 days before nematode inoculation and with foliar spray 3 days after nematode inoculation treatments, respectively (Fig. 4).

Similar results recorded with shoot weight, the obtained data showed that all tested amino acids expect methonine increased significantly root fresh weight of treated plants in all treatments compared to control.

The highest absolute values of root fresh weight (8.2 and $5.4 \mathrm{~g}$ ) were recorded with asparagine and arginine amino acids with the treatment of soil drench three days before nematode application, respectively (Fig. 5).

The influences of the four tested amino acids on nematode infection were assessed under greenhouse conditions. Significant differences between amino acids (valine, methonine, arginine and asparagine) as well as between application methods (soil drench and foliar spray) at two different application times (three days before and three days after nematode inoculation) were recorded.

The relative lowest number of galls/root system i.e. 9, 16 and 17 was recorded with arginine, valine and methonine amino acids at soil drench three days before nematode inoculation treatments, respectively (Fig. 6).

Contrary, the highest number of galls/root system (85 and 79) was recorded with methonine and asparagine amino acids in foliar spray three days after nematode inoculation treatments, respectively (Fig. 6).

Similar to the results recorded with number of galls, the lowest number of egg masses (1.3 and 4.3) was recorded with arginine amino acid in soil drench treatments three days before nematode inoculation and three days after nematode inoculation times, respectively (Fig. 7).

The obtained results illustrated that all tested amino acids reduced significantly compared to the control either when they applied as soil drench or foliar spray (fig.8). The absolute lowest number of second stage juveniles per $250 \mathrm{~g}$ soil was recorded with DL-arginine (fig.8). 


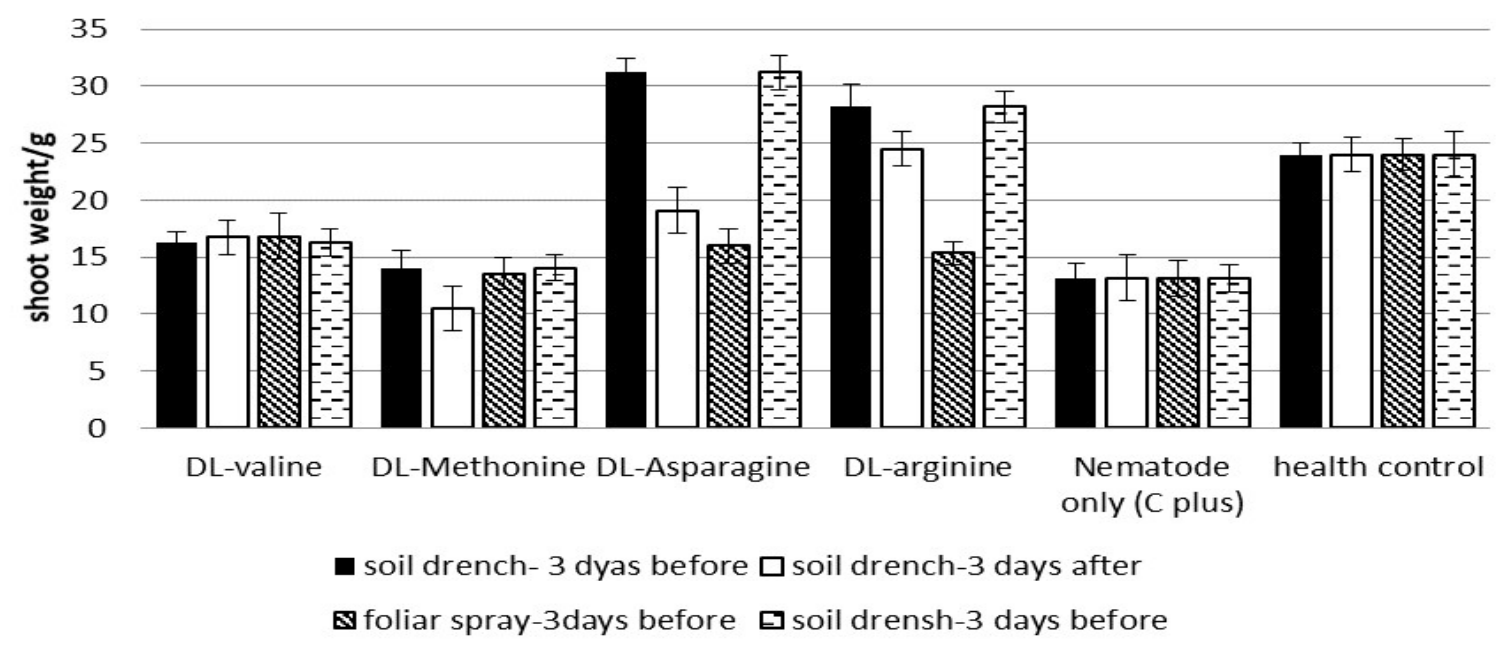

Fig. (4). Shoot fresh weight recorded with treated and untreated tomato plants with valine, methonine, asparagine and arginine amino acids using soil drench and foliar spray application methods at 3 days before and after nematode inoculation times.

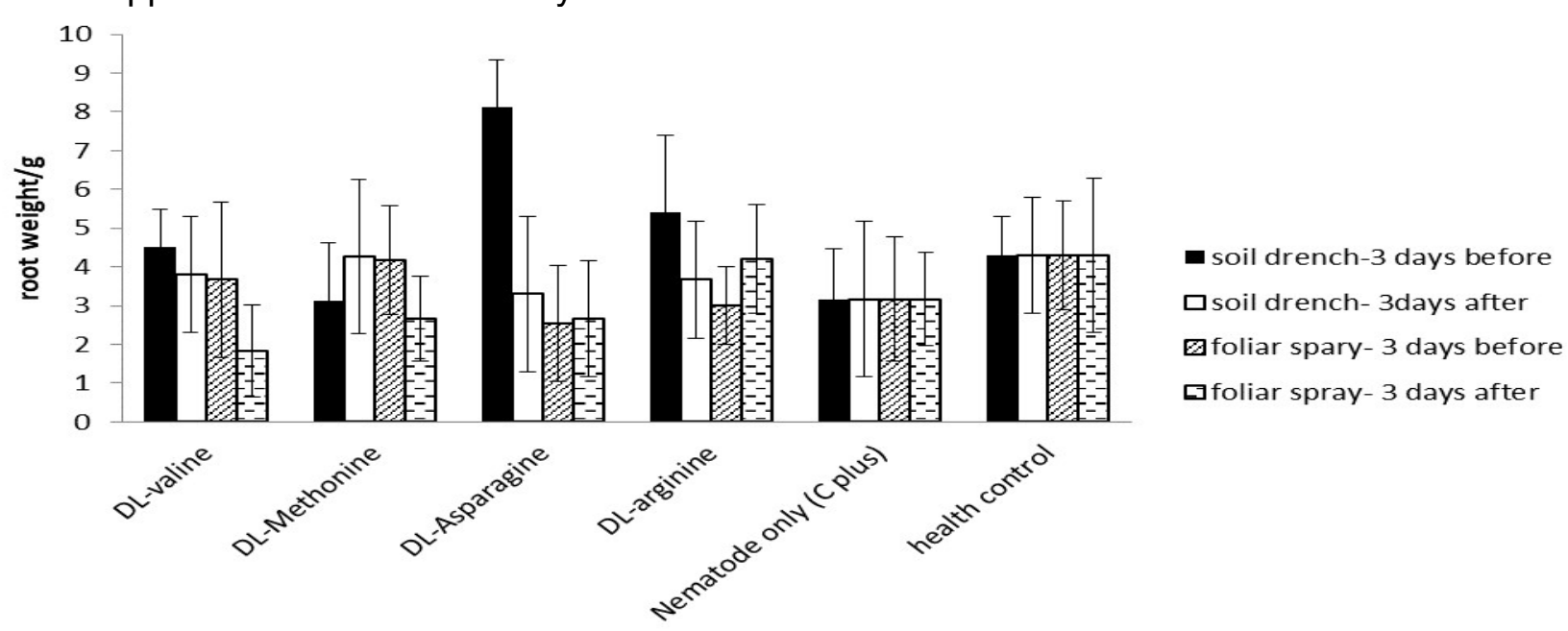

Fig. (5). Root weight recorded with treated and un-treated tomato plants with valine, methonine, asparagine and arginine amino acids using soil drench and foliar spray application methods at 3 days before and after nematode inoculation times. 100

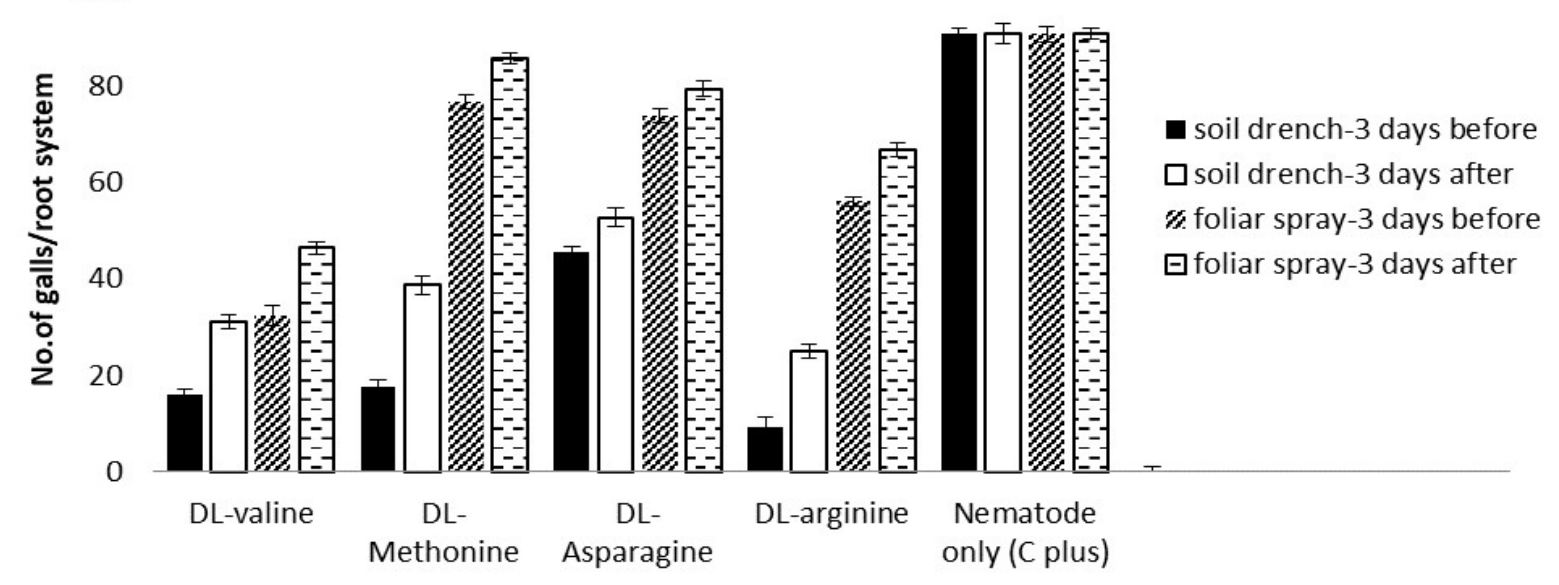

Fig. (6). Number of galls/root system recorded with treated and un-treated tomato plants with valine, methonine, asparagine and arginine amino acids using soil drench and foliar spray application methods at 3 days before and after nematode inoculation times. 


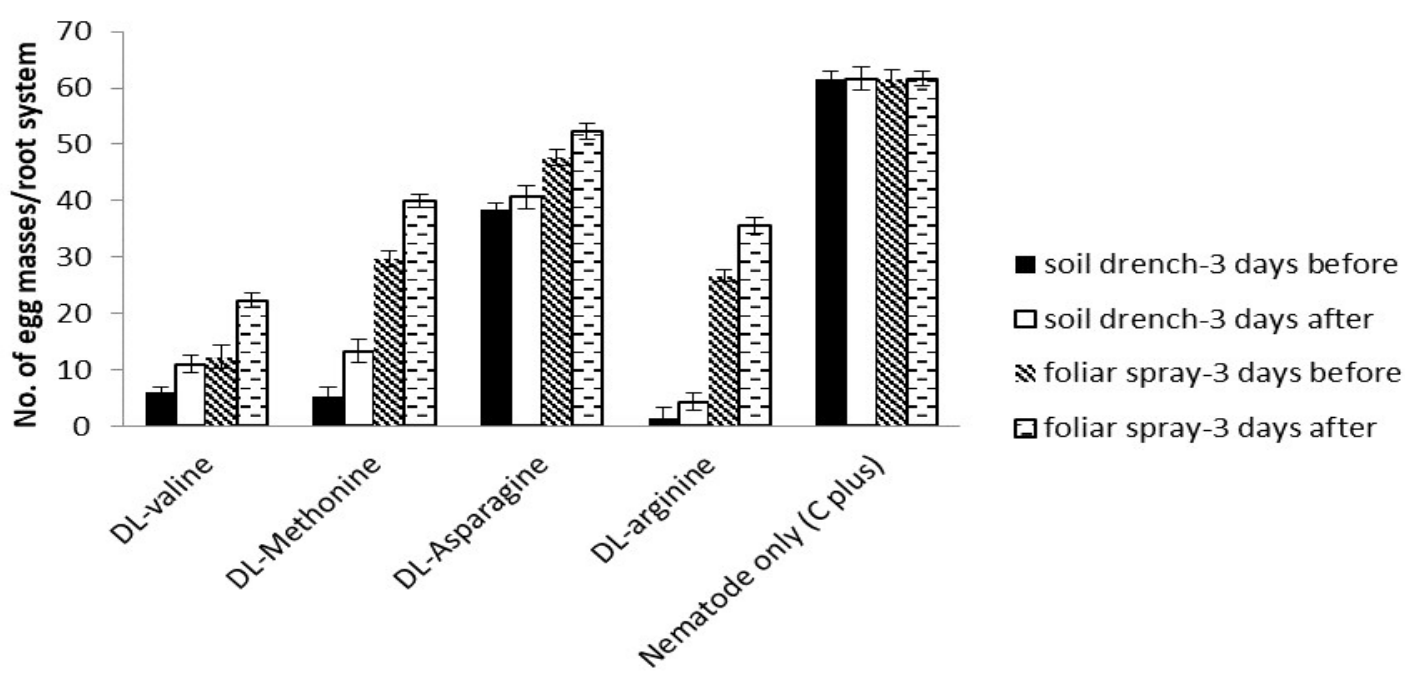

Fig. (7). Number of egg masses/root system recorded with treated and un-treated tomato plants with valine, methonine, asparagine and arginine amino acids using soil drench and foliar spray application methods at 3 days before and after nematode inoculation times.

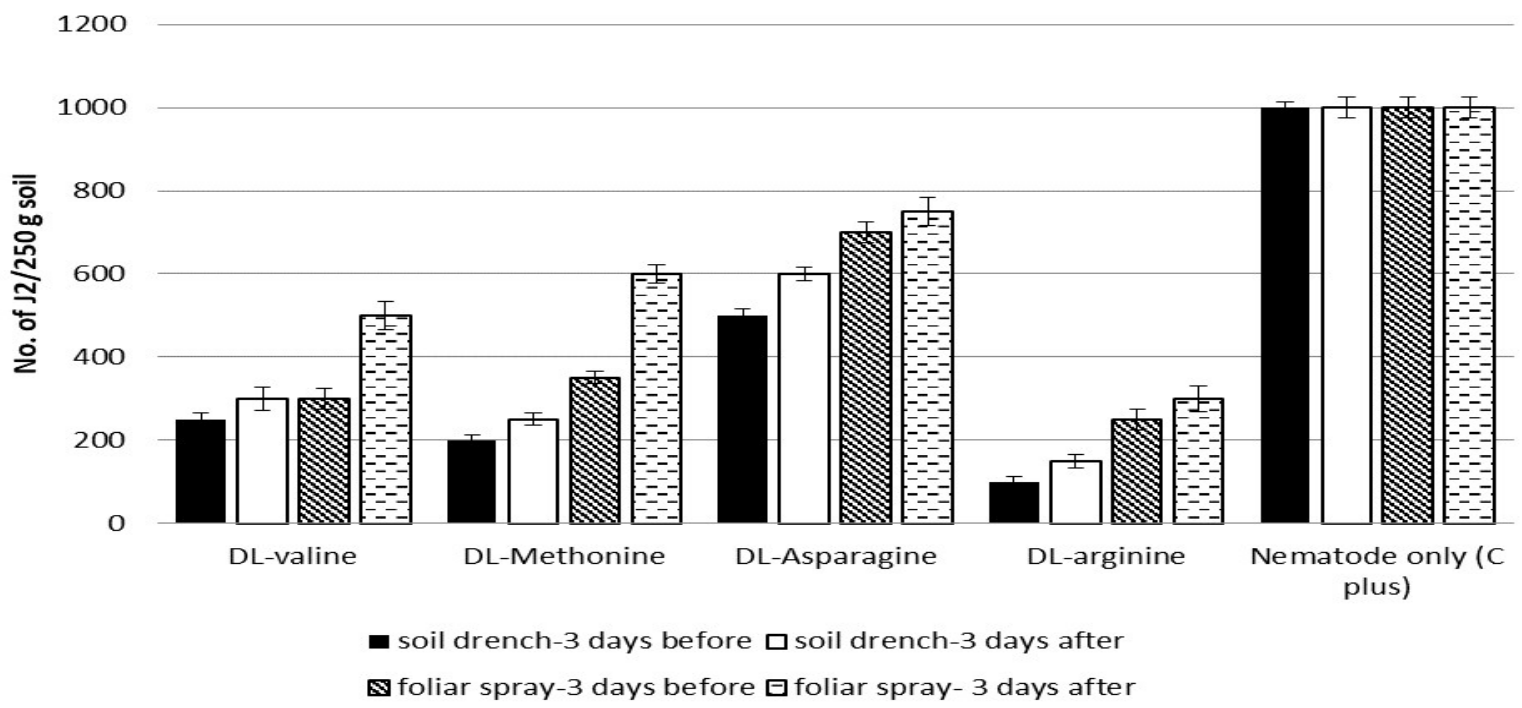

Fig. (8). Number of $\mathrm{J}_{2} / 250 \mathrm{~g}$ soil recorded with treated and un-treated tomato plants with valine, methonine, asparagine and arginine amino acids using soil drench and foliar spray application methods at three days before and after nematode inoculation times.

The results showed that the highest peroxidase activity (0.95) was recorded with DL-Arginine when applied as a soil drench 3 days before nematode inoculation (table 1), while the lowest enzyme value was recorded with DL-Methonine as a foliar spray at 3 days post nematode inoculation treatment. Similar results were recorded also with aspect to polyphenoloxidase activity. Thus the highest enzyme activity (0.92) was recorded with DL-Arginine and DLValine when applied as a soil drench at 3 days before nematode inoculation time (table1). The analysis of catalase enzyme was consistent with the other evaluated enzymes (peroxidase and ployphenoloxidase) as the arginine amino acid used as soil drench at 3 days before nematode inoculation resulted in highest catalase activity (0.38). 
Table (1). Effect of the tested amino acids applied as soil drench and foliar spray at three days before and after nematode inoculation on the activity of antioxidant enzymes, peroxidase, polyphenoloxidase and catalase in tomato plants.

\begin{tabular}{|c|c|c|c|c|c|}
\hline Treatments & $\begin{array}{c}\text { Type of } \\
\text { application }\end{array}$ & $\begin{array}{c}\text { Time of } \\
\text { application }\end{array}$ & $\begin{array}{l}\text { Peroxidase } \\
\text { (O.D. } \text { g }^{-1} \text { fr.wt. } \\
\text { after } 2 \text { min.) }\end{array}$ & $\begin{array}{l}\text { Polyphenoloxidase } \\
\text { (O.D. g-1 fr.wt. after } \\
45 \text { min.) }\end{array}$ & $\begin{array}{l}\text { Catalase } \\
\text { (mg/g- } \\
{ }^{1} \text { fr.wt.) }\end{array}$ \\
\hline \multirow{4}{*}{ DL-Valine } & \multirow{2}{*}{ Soil drench } & 3 days before & 0.90 & 0.92 & 0.25 \\
\hline & & 3 days after & 0.86 & 0.86 & 0.22 \\
\hline & \multirow{2}{*}{$\begin{array}{l}\text { Foliar } \\
\text { spray }\end{array}$} & 3 days before & 0.80 & 0.83 & 0.20 \\
\hline & & 3 days after & 26.87 & 0.81 & 0.20 \\
\hline \multirow{4}{*}{$\begin{array}{l}\text { DL- } \\
\text { Methonine }\end{array}$} & \multirow{2}{*}{ Soil drench } & 3 days before & 0.93 & 0.93 & 0.29 \\
\hline & & 3 days after & 0.81 & 0.84 & 0.19 \\
\hline & \multirow{2}{*}{$\begin{array}{l}\text { Foliar } \\
\text { spray }\end{array}$} & 3 days before & 0.59 & 0.60 & 0.18 \\
\hline & & 3 days after & 0.28 & 0.27 & 0.20 \\
\hline \multirow{4}{*}{$\begin{array}{l}\text { DL- } \\
\text { Asparagine }\end{array}$} & \multirow{2}{*}{ Soil drench } & 3 days before & 0.70 & 0.69 & 0.25 \\
\hline & & 3 days after & 0.54 & 0.71 & 0.23 \\
\hline & \multirow{2}{*}{$\begin{array}{l}\text { Foliar } \\
\text { spray }\end{array}$} & 3 days before & 0.56 & 0.56 & 0.22 \\
\hline & & 3 days after & 0.37 & 0.31 & 0.20 \\
\hline \multirow{4}{*}{$\begin{array}{l}\text { DL- } \\
\text { Arginine }\end{array}$} & \multirow{2}{*}{ Soil drench } & 3 days before & 0.95 & 0.92 & 0.38 \\
\hline & & 3 days after & 0.89 & 0.90 & 0.30 \\
\hline & \multirow{2}{*}{$\begin{array}{l}\text { Foliar } \\
\text { spray }\end{array}$} & 3 days before & 0.71 & 0.69 & 0.22 \\
\hline & & 3 days after & 0.69 & 0.69 & 0.23 \\
\hline $\begin{array}{l}\text { Nematode } \\
\text { alone (C+) }\end{array}$ & & & 0.18 & 0.21 & 0.16 \\
\hline $\begin{array}{l}\text { Health } \\
\text { control }\end{array}$ & & & 0.33 & 0.36 & 0.21 \\
\hline
\end{tabular}

Results in Fig. (9) revealed that all tested amino acids significantly reduced the nematode final population compared to plants treated with nematode alone.

The highest reduction obtained with DL-arginine amino acid when applied as a soil drench 3 days before nematode inoculation, followed by DL-methonine as a soil drench 3 days before nematode inoculation recorded. The lowest effect recorded with DL-aspragine.

Results in Fig. (10) confirmed that DLarginine was the effective one in reducing the nematode reproduction when compared with the other amino acids. DL-valine came in the second rank after DL-arginine, whereas DLasparagine the least effective one.

Results revealed also that applying the amino acids generally as a soil drench 3 days before nematode inoculation achieved highest reduction in nematode reproduction, followed by soil drench 3 days after nematode inoculation. Application the amino acids as a foliar spray 3 days after nematode inoculation was the lowest one in reducing the nematode reproduction as shown in Fig. (11). 


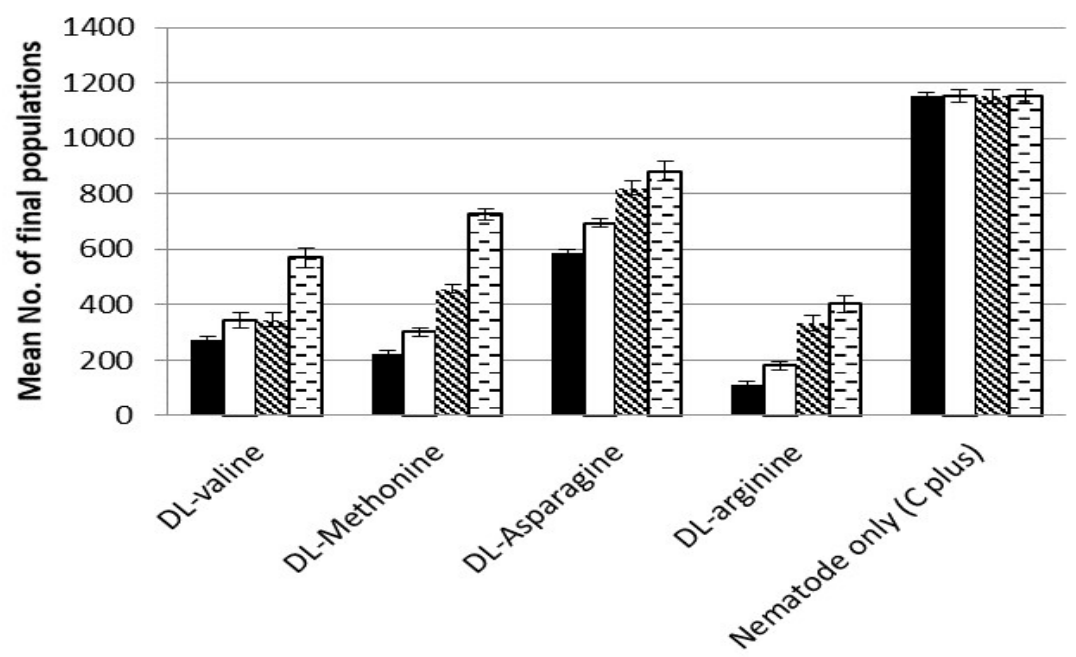

- soil drench-3 days before $\square$ soil drench-3 days after s foliar spray-3 days before 曰foliar spray-3 days after

Fig. (9). Nematode final population recorded with treated and un-treated tomato plants with valine, methonine, asparagine and arginine amino acids using soil drench and foliar spray application methods at 3 days before and after nematode inoculation times.
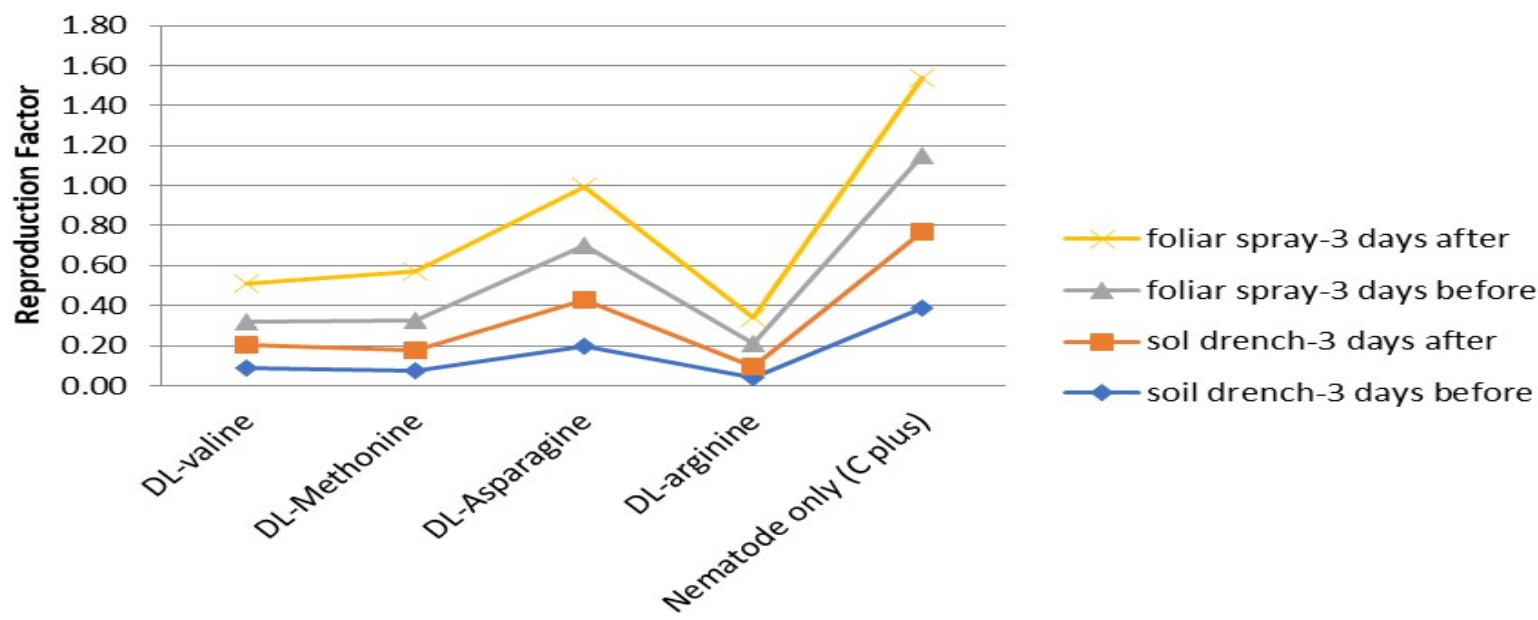

Fig. (10). Reduction factor (Rf) recorded with treated and un-treated tomato plants with valine, methonine, aspraragine and arginine amino acids using soil drench and foliar spray application methods at 3 days before and after nematode inoculation.

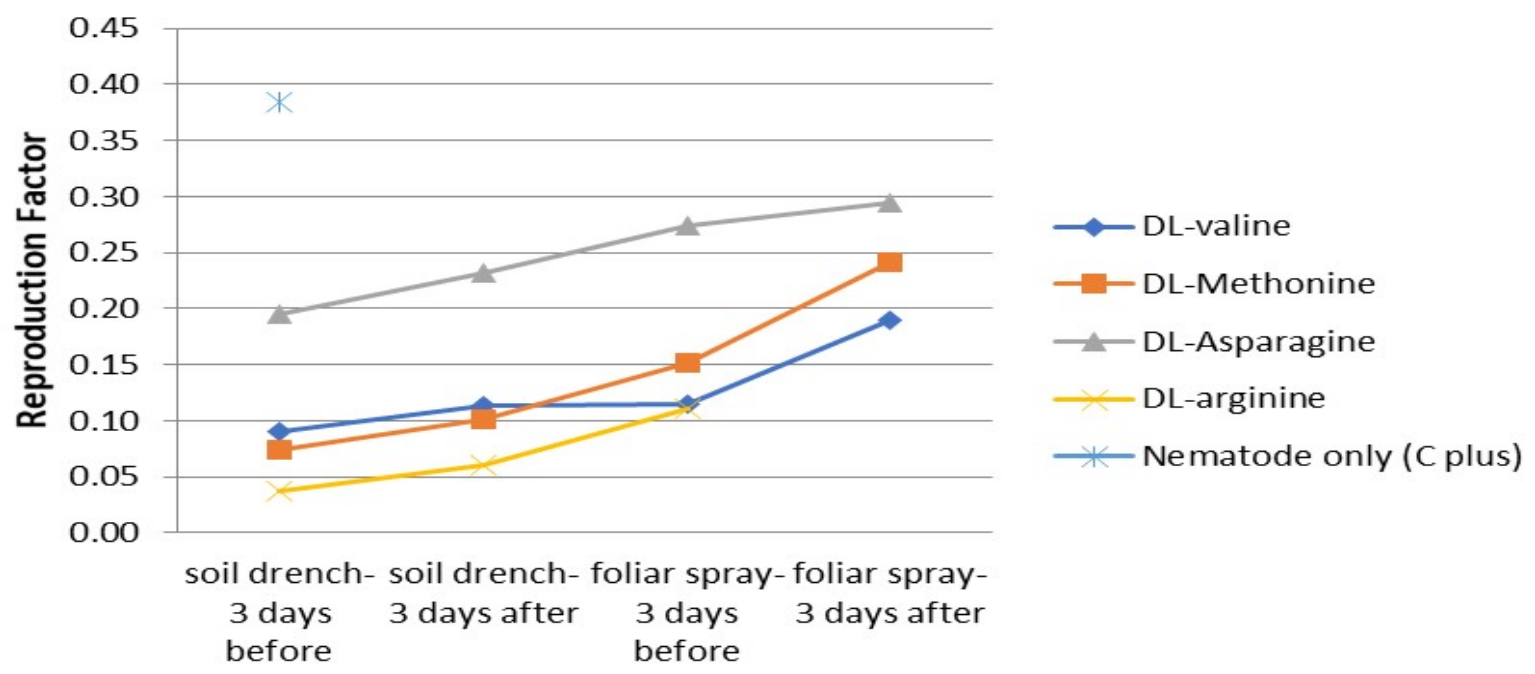

Fig. (11). Effect of different application types and times of four different amino acids on reproduction factor of $M$. javanica on tomato plants. 


\section{DISCUSSION}

Some amino acids have been found to inhibit egg hatching and juveniles survival as well as nematode galling caused of Meloidogyne species under both in vitro and in vivo conditions (Osman, 2013). He reported also, different amino acids and vitamins application have been resulted in reducing the hatching of Meloidogyne incognita eggs, number of root galls as well as mortality and fecundity of nematode females. Role of amino acids in resistance mechanisms of host plants against root-knot nematodes have been reported by many studies (Osman, 2013; Amdadul et al., 2014). Furthermore, Osman (2013) reported also that amino acids may have a repellent effect toward $M$. javanica larvae. He suggested also that L-arginine and ascorbic acid have nematicidal activity and might produce promising some anti-metabolites which can play role in biological control of $M$. javanica.

Amdadul et al., (2014) found that the effect of 6 amino acids viz. DLmethonine, DL-valine, DL-serine, DLphenylalanine, DL-proline, and DLhistidine were found to give significantly lower response in relation to hatching of egg masses and survival of $\mathrm{J}_{2}$ compared to the control treatment. Significant variations in hatching and survival response were also found among the treatments from lower to higher doses.

Reddy (1975) reported the inhibition of egg masses of $M$. incognita was referred to contact toxicity of DL-amino acids. With the increase of doses, the variation in hatching was found to be reduced among the treatment indicating their lethal effect on hatching. Inhibition of egg hatching increased with increasing doses of all amino acids (Rekha et al., 1993). Reddy et al., (1975) reported that DLamino acids had some contact toxicity in vitro to the second stage juveniles of $M$. incognita. Decrease in survival $\mathrm{J}_{2}$ was thought to be due to lethal effect as many of the DL-amino acids like DLmethonine and DL-phenyl-alanine as well as L-proline and L-histidine were found to be lethal to $J_{2}$ as stated by Reddy et al., (1974).

Osman (1993) found 100\% mortality of $M$. javanica with increasing concentrations of L-arginine and Lglutamic acid from 1000 to $2000 \mathrm{ppm}$. Amdadul et al., (2014) investigate six different amino acids and found that the all tested amino acids were lethal to the survival of $\mathrm{J}_{2}$ juveniles of Meloidogyne spp. to varying degrees at their different concentrations. They added also, DLphenyl-alanine appeared to give maximum response in plant growth characters like length of shoot and root, fresh weight of shoot and root correspondingly with the lowest galling incidence. Evans and Trudgill (1971) forward that amino acids have chemotherapeutic effects on some diseased plants and they accumulated in the giant cells of nematode-infested plants and they might be used as nematicides. They revealed also some amino acids inhibited reproduction of Trichodorus christiei Allen and Helicotylenchus nannus Steiner and decreased galling of tomato roots by $M$. incognita.

Eight amino acids tested against four species of nematodes, DL-methonine and DL-alanine decreased number of 
Heterodera avenae (Woll) cysts on oats and the numbers of Ditylenchus dipsaci (Kuehn) on oats, while DL-butyric acid decreased the number of Aphelenchoids ritzemabosi (Schwartz) on lucerne (Evans and Trudgill, 1971). Kim and Whang (2012) investigated the lethal effects of $J_{2}$ juveniles for 19 types of commercial amino acids. Five kinds of amino acids (L-asparagine, L-asparatic, L-methonine, L-tyrosine, L-cystein) showed mortality rate of more than $50 \%$ at a concentration of $50 \mathrm{mM}$, while Lasparagine showed the highest mortality rate at $94 \%$.

Kesba (2003) indicated the accumulating of protein in roots as a result of grape roots chemical analysis that accumulation of proteins in roots may reach toxic limits due to amino acids spray application and may have a direct toxic action as a result of exuberance of such chemicals in giant cells. Amdadul et al., (2014) revealed that with the increase of the doses, the variation in hatching was found to be reduced among the treatments indicating their lethal effect on egg hatching.

Masood and Husain (1975) observed the best plant growth with phenyl-alanine applied as soil drench to eggplant inoculated with $M$. incognita. They also observed higher plant growth with proline applied as soil drench. Amdadul et al., (2014) found that with respect to development of $M$. javanica in six amino acids treated tomato plants, other than egg masses all the amino acids gave identical response with a reduced number of adult females, $\mathrm{J}_{2}$ and $\mathrm{J}_{4}$ juvenile stages compared to control.
Prasad and Webstar (1967) revealed that several amino acids were used as anti-metabolites for nematodes control. They found that also application of DLamino butyric to soil effectively reduced the number of galls induced by Nacobbus serendipiticus on tomato roots without the host plant even through a much higher concentration of the amino acid $(150 \mathrm{mg} / 10 \mathrm{ml})$ was applied to the soil 2 weeks after inoculation with the nematode. Tsai and Van Gundy (1988) found that a soil drench with DLmethonine, which is not nematicide, reduced the size of galls caused by $M$. incognita. They revealed also that DLmethonine was believed to interact with root exudates, subsequently immobilizing the nematode.

Prasad and Webstar (1967) revealed that the exact mechanism of nematodes control by amino acids has not clarified, but D-amino acids are believed to concentrate near root tips, the initial nematode feeding site thereby blocking essential metabolic pathways in either the plant or nematode and interfering with nutrition. Several amino acids such as DL-methonine, DL-amino butryic acid, DL- and L- proline have been used in soil drenches as anti-metabolites for nematode and have reduced nematode damage as reported by (Epstein, 1972; Prasad and Webster, 1967; Tasi and Van Gundy, 1988).

Applications of amino acids as foliar sprays inhibited reproduction, galling by $M$. incognita and $M$. javanica and retarded nematode development maturity, egg mass formation, egg productions and improved plant growth as reported by (Al-Sayed, 1992 and Kesba 1999 and 2003). 


\section{REFERENCES}

Alam, M.M. (1987). Pollution free control of plant parasitic nematodes by soil amendments with plant wastes. Biol. Astes. 22: 75-79.

Al-Sayed, A.A. (1992). Effect of ascorbic acid and L-arginine on controlling Meloidogyne incognita as influenced by soil temperature. Annals of Agric. Sci., Moshtohor, 30 (3): 1549-1557.

Amdadul, A.K.M.; Rejwan, B.M.D.; Khan, I.A.K.; Mahmed, A. and Uddin, A.M. (2014). Effect of amino acids on rootknot nematode (Meloidogyne javanica) infecting tomato plant. Archives of Phytopathology and Plant Protection, 47 (16): 1921-1928.

Bach, A.N. and Oparin, A.E. (1968). Research methods in bacterial causes of plants, pp. 184-187.

Broesh, S. (1954). Colorimetric assay of phenoloxidase. Bull. Sac. Chem. Biol., 36: 711-713.

Daykin, M.E. and Hussey, R.S. (1985). Staining and histopathological techniques in Nematology, In: Barker, K.R.; Carter, C.C. and Sasser, J.N. (eds). An Advanced Treatise on Meloidogyne, Vol. II Methodology, pp. 39-48.

Epstein, E. (1972). Effect of pretreatment with some amino acids and amino acid antimetabolites on Longidorus africanus infected and non-infected Bidens tripartite. Nematologica, 18: 555-562.

Evans, K. and Trudgill, D.L. (1971). Effects of amino acids on the reproduction of Heterodera rostochiensis. Nematologia, 17: 495500.
FAOSTAT (2020). Annual statistical agriculture data for Arab Republic of Egypt C.F. Statistical agriculture data of agriculture and reform lands ministry Egypt.

Fehrman, H. and Dimond, A.E. (1967). Peroxidase activity and Phytophthora resistance in different ranges of potato. Plant Pathology, 57: 69-72.

Goodey, J.B. (1957). Laboratory methods for work with plant and soil nematodes. Tech. Bull. No. 2, Min. Agric. Fish, Ed. London, pp 47.

Hussain, J.; Khan, F.U.; Ullah, R.; Muhammad, Z.; Rehman, N.U.; Shinwari, Z.K.; Khan, I.U.; Zohaib, M.; Imad-ud-din and Hussain, A.M. (2011). Nutrient evaluation and elemental analysis of four selected medicinal plants of Khyber Pakhtoon Kkhwa, Pakistan. Pak. J. Bot. 43 (1): 427-434.

Hussey, R.S. and Barker, K.R. (1973). A comparison of methods of collecting inocula of Meloidogyne spp including a new technique. Plant Dis. Rep. 57: 1025-1028.

Kesba, H.H. (1999). Ecological and pathological studies on some plant parasitic nematodes infecting grape, Vitis vinifera L. M. Sc. Thesis, Fac. Agric., Cairo Univ., 114 pp.

Kesba, H.H. (2003). Integrated nematode management on grapes grown in sandless soil. Ph.D. Thesis, Fac. Agric., Cairo Univ., 189 pp.

Kim, S.J. and Whang, K.S. (2012). Nematicidal effect of root-knot nematode (Meloidogyne incognita) by amino acids biochemical agent 
extracted from chicken feather. J. Appl. Biol. Chem., 55 (4): 247-252.

Masood, A. and Husain, S.I. (1975). Effect of amino acids on plant growth and root-knot disease development in brinjal Solanum melongena. Indian J. Mycol. Plant Pathol., 5: 1-6.

Norton, D.C. (1978). Ecology of plant parasitic nematode. John Willey and Sons, New York, p. 238.

Oka, Y.; Spiegel, Y. and Cohen, Y. (2000). $\beta$-amino-butryic acid induced resistance in plants against nematodes. Phytoparasitica, 28 (3): 274.

Osman, G.Y. (1993). Effect of amino acids and ascorbic acid on Meloidogyne javanica Anz Schadlingskde Pflanzenschutz Umweltschutz, 66: 140-143.

Prasad, S.K. and Webster, J.M. (1967). The effect of amino acid antimetabolites on four nematode species and their host plant. Nematologica, 13: 318-323.

Reddy, P.P. (1975). Studies on the action of amino acids on the root-knot nematode, Meloidogyne incognita. Mysore J. Agric. Sci., 9: 7-11.
Reddy, P.P.; Govindu, H.C. and Setty, K.G.H. (1975a). Studies on the effect of amino acids on the root-knot nematode Meloidogyne incognita infecting tomato. Indian J. Nematol., 5: 36-41.

Reddy, P.P.; Govindu, H.C. and Setty, K.G.H. (1975b). Amino acids can be used to control plant parasitic nematodes. Current Res., Dept. of Plant Pathol., Univ. of Agric. Sci.; Bangalore, India; No. 3: 32.

Rekha, A.; Saxena, S.K. and Arya, R. (1993). Effect of culture filtrate of Fusarium oxysporum f.sp. lycopersici grown on different amino acids on hatching of Meloidogyne incognita . Indian Phytopathol., 46: 167-168.

Taylor, A.L. and Sasser, J.N. (1978). Biology, identification and control of root-knot nematodes (Meloidogyne spp Cobb). Pub. Dept. Plant Pathol., North Carolina. State Univ., \& U.S. Agency Int. Dev. Raleigh, N.C. 111 pp.

Tsai, B.Y. and Van Gundy, S.D. (1988). Effect of DL-methonine on host response to root-knot nematodes. (Abstr.) J. Nematol., 20: 661-662.

Received: April 19, 2019.

Revised: June 22, 2019.

Accepted: June 25, 2019. 